\title{
Sargassum fulvellum Protects HaCaT Cells and BALB/c Mice from UVB-Induced Proinflammatory Responses
}

\author{
Chan Lee, ${ }^{1}$ Gyu Hwan Park, ${ }^{2}$ Eun Mi Ahn, ${ }^{3}$ Chan-Ik Park, ${ }^{4}$ and Jung-Hee Jang ${ }^{1}$ \\ ${ }^{1}$ Department of Pharmacology, School of Medicine, Keimyung University, 2800 Dalgubeoldaero, Dalseo-gu, \\ Daegu 704-701, Republic of Korea \\ ${ }^{2}$ Research Institute of Pharmaceutical Sciences, College of Pharmacy, Kyungpook National University, \\ Daegu 702-701, Republic of Korea \\ ${ }^{3}$ Department of Herbal Foodceutical Science, Daegu Haany University, Gyeongsangbuk-do 712-230, Republic of Korea \\ ${ }^{4}$ Department of Cosmeceutical Science, Daegu Haany University, 290 Yugok-dong, Gyeongsan-si, \\ Gyeongsangbuk-do 712-230, Republic of Korea \\ Correspondence should be addressed to Chan-Ik Park; cipark@dhu.ac.kr and Jung-Hee Jang; pamy202@kmu.ac.kr
}

Received 29 November 2012; Accepted 10 June 2013

Academic Editor: Vernon A. Barnes

Copyright (C) 2013 Chan Lee et al. This is an open access article distributed under the Creative Commons Attribution License, which permits unrestricted use, distribution, and reproduction in any medium, provided the original work is properly cited.

\begin{abstract}
Ultraviolet (UV) radiation has been reported to induce cutaneous inflammation such as erythema and edema via induction of proinflammatory enzymes and mediators. Sargassum fulvellum is a brown alga of Sargassaceae family which has been demonstrated to exhibit antipyretic, analgesic, antiedema, antioxidant, antitumor, fibrinolytic, and hepatoprotective activities. The purpose of this study is to investigate anti-inflammatory effects of ethylacetate fraction of ethanol extract of Sargassum fulvellum (SFEEtOAc) in HaCaT keratinocytes and BALB/c mice. In HaCaT cells, SFE-EtOAc effectively inhibited UVB-induced cytotoxicity $\left(60 \mathrm{~mJ} / \mathrm{cm}^{2}\right)$ and the expression of proinflammatory proteins such as cyclooxygenase-2 (COX-2), tumor necrosis factor- $\alpha$ (TNF$\alpha$ ), and inducible nitric oxide synthase (iNOS). Furthermore, SFE-EtOAc significantly reduced UVB-induced production of proinflammatory mediators including prostaglandin $\mathrm{E}_{2}\left(\mathrm{PGE}_{2}\right)$ and nitric oxide $(\mathrm{NO})$. In $\mathrm{BALB} / \mathrm{c}$ mice, topical application of SFE-EtOAc prior to UVB irradiation $\left(200 \mathrm{~mJ} / \mathrm{cm}^{2}\right)$ effectively suppressed the UVB-induced protein expression of COX-2, iNOS, and TNF- $\alpha$ and subsequently attenuated generation of $\mathrm{PGE}_{2}$ and $\mathrm{NO}$ as well. In another experiment, SFE-EtOAc pretreatment suppressed UVB-induced reactive oxygen species production and exhibited an antioxidant potential by upregulation of antioxidant enzymes such as catalase and $\mathrm{Cu} / \mathrm{Zn}$-superoxide dismutase in $\mathrm{HaCaT}$ cells. These results suggest that SFE-EtOAc could be an effective anti-inflammatory agent protecting against UVB irradiation-induced skin damages.
\end{abstract}

\section{Introduction}

Skin is the body's largest organ acting as an effective barrier thereby always at a risk of continuous exposure to diverse environmental stimuli including solar ultraviolet (UV). UV radiation is divided into three categories depending on main wavelength ranges such as UVA (long wave, 320$400 \mathrm{~nm}$ ), UVB (mid wave, 290-320 nm), and UVC (short wave, 200-290 nm) [1]. Particularly, UVB irradiation serves as an important etiologic factor causing inflammatory skin damages, oxidative stress, DNA damage, cellular as well as tissue injuries, cell death, skin cancer, and premature skin aging $[1,2]$.
UVB exposure on the skin stimulates the inflammatory responses via upregulation of proinflammatory cytokines such as tumor necrosis factor- $\alpha$ (TNF- $\alpha$ ), interleukin- $1 \alpha$ (IL$1 \alpha$ ), IL-1 $\beta$, IL-6, and IL-8 [3] and prostaglandins (PGs) such as $\mathrm{PGE}_{2}$ and $\mathrm{PGD}_{2}$, which were produced by enhanced expression of cyclooxygenase-2 (COX-2) [4]. COX-2 is a rate-limiting enzyme in the biosynthesis of PGs from arachidonic acids and can be stimulated by some cytokines under inflammatory conditions [5]. UVB irradiation also triggers the production of nitric oxide (NO) which is implicated in the pathogenesis of various inflammatory skin disorders [6]. NO is generated by the enzymatic action of inducible nitric oxide synthase (iNOS) which is strongly induced by microbial 
infection, inflammatory cytokines, and environmental insults in diverse types of cells $[6,7]$.

Most of the harmful effects of UVB radiation are also associated with the intracellular accumulation of reactive oxygen species (ROS) such as hydrogen peroxide, superoxide anions, and hydroxyl radicals which ultimately lead to oxidative damages [8]. To protect against UVB-induced oxidative stress there are diverse endogenous antioxidant defense systems in our body. However, depletion of endogenous antioxidant enzymes as well as antioxidants in the skin during UVB-mediated oxidative stress results in cellular as well as tissue damages and eventually leads to apoptotic cell death [9].

Therefore, there has been considerable interest in searching for naturally occurring plant products for the prevention and protection from UV-induced skin photodamages. The photoprotective effects of green tea polyphenols, grape seed proanthocyanidins, silymarin, and genistein against UVB-induced skin inflammation, oxidative stress, and DNA damages have been largely studied, and their underlying mechanisms have been suggested using in vitro cell cultures as well as in vivo animal models [1].

Recently, attention has been focused on extracts, fractions, and single compounds derived from marine algae with antioxidant and anti-inflammatory properties. Sargassum fulvellum (SF), a brown alga of Sargassaceae family, is one of the candidates. It has been widely used as a food additive and medicinal purpose in oriental medicine to treat lump, dropsy, swollen, and painful scrotum, and urination problems [10]. Particularly, the dichloromethane extract of SF was reported to have antiedema, antipyretic, and analgesic activities [10]. The freeze-dried SF protected against D-galactosamine-induced hepatopathy in Wistar rats [11]. Polysaccharide fraction obtained by fractional precipitation with ethanol from hot water extract of SF exhibited antitumor activity [12]. In addition, two fibrinolytic compounds were isolated, purified, and characterized from SF [13].

However, the effect of SF on UVB-induced inflammatory skin damages and its underlying molecular mechanisms have not been studied and remain largely unresolved. Therefore, the purpose of this study is to investigate the protective effect of SF against the UVB-induced pro-inflammatory responses in vitro $\mathrm{HaCaT}$ human keratinocytes as well as in vivo $\mathrm{BALB} / \mathrm{c}$ mice and to further elucidate its antioxidant potentials as a possible mechanism of skin protection.

\section{Materials and Methods}

2.1. Plant Materials. Thalli of Sargassum fulvellum (SF) was purchased from JukDo market (Pohang, Korea), and voucher specimen is deposited in Department of Cosmeceutical Science, Daegu Haany University (Gyeongsan, Korea). Dried SF $(150.0 \mathrm{~kg}$ ) powder was extracted with $95 \%$ ethanol (EtOH) for $72 \mathrm{~h}$ at room temperature and then evaporated in vacuo. The final yield was $0.29 \%$. The ethanol extract of SF was further successively partitioned with water $(300 \mathrm{~mL})$, ethylacetate $($ EtOAc, $300 \mathrm{~mL} \times 3)$, and $n$-butanol $(n-\mathrm{BuOH}, 300 \mathrm{~mL} \times 3)$. The ethylacetate fraction of SF ethanol extract (SFE-EtOAc) was dried in a rotary evaporator. SFE stock solution was prepared with dimethyl sulfoxide (DMSO) and acetoneolive oil $(3: 1)$ for the cell cultures and animal experiments, respectively.

2.2. Chemical Materials. Cell culture medium (Dulbecco's modified Eagle's medium, DMEM), fetal bovine serum (FBS), and antibiotics (penicillins/streptomycin) were purchased from Gibco BRL (Rockville, MD, USA). Primary anti-COX2 , anti-TNF- $\alpha$, and anti-iNOS antibodies and horseradish peroxidase-conjugated secondary anti-rabbit antibody were the products of Santa Cruz Biotechnology (Santa Cruz, CA, USA). Antiactin antibody, MTT [3-(4,5-dimethylthiazol-2yl)-2,5-diphenyl tetrazolium bromide], and other chemicals were obtained from Sigma-Aldrich (St. Louis, MO, USA). $2^{\prime} 7^{\prime}$-Dichlorofluroscein diacetate (DCF-DA) dye was supplied from Invitrogen Co. (Carlsbad, CA, USA).

2.3. Cell Culture and Treatment. Immortalized human keratinocytes, HaCaT cells were cultured in DMEM supplemented with $10 \%$ fetal bovine serum and antibiotic mixture (100 units/mL penicillin and $100 \mu \mathrm{g} / \mathrm{mL}$ streptomycin) and routinely maintained in a humidified atmosphere containing $5 \% \mathrm{CO}_{2}-95 \%$ air at $37^{\circ} \mathrm{C}$. The culture medium was changed every other day, and cells were seeded at the appropriate density for further experiments. HaCaT cells were pretreated with ethylacetate fraction of SF ethanol extract (SFE-EtOAc) for $9 \mathrm{~h}$ and then exposed to UVB (280-320 nm, peak emission at $312 \mathrm{~nm}, 60 \mathrm{~mJ} / \mathrm{cm}^{2}$ ) using a UVB irradiation equipment (BLX-E254, Vilber Lourmat, France). During the UVB exposure, cells were kept in a thin layer of phosphate-buffered saline (PBS), and then, PBS was replaced with culture medium containing $1 \%$ DMSO (vehicle control) or SFEEtOAc.

2.4. Experimental Animals and Treatment. BALB/c mice (male, 6-8 weeks old) were purchased from DaeHan Biolink Co., Ltd. (Daegu, Korea). The animals were maintained in standard conditions $\left(21-25^{\circ} \mathrm{C}\right.$ temperature, $40-60 \%$ humidity, and $12 \mathrm{~h}$ light- $12 \mathrm{~h}$ dark cycle) with free access to foods and water. Animals were housed and handled in accordance with the Institutional Animal Care and Use Guidelines of the Daegu Haany University and National Institute of Health. After shaving the dorsal side of the skin by a clipper, mice in the resting phase of the hair cycle were used in the following experiments. Vehicle (acetone-olive oil, 3:1) or SFE-EtOAc was topically applied to the back of each mouse, and after $30 \mathrm{~min}$, mice were exposed to $200 \mathrm{~mJ} / \mathrm{cm}^{2} \mathrm{UVB}$ (BLX-E254) in a specially designed cage. The exact dosage of UVB was closely monitored by spectroradiometer (UVP, CA, USA).

2.5. Cell Viability Assay (MTT Dye Reduction Assay). To determine the safety and protective effect of SFE-EtOAc, cell viability was measured by MTT assay which is based on the mitochondrial enzyme-dependent reduction of MTT dye to purple formzan. After incubation of UVB-exposed HaCaT cells with or without SFE-EtOAc, MTT solution $(5 \mathrm{mg} / \mathrm{mL}$ in PBS) was added to each well and additionally treated for $2 \mathrm{~h}$. Finally, the medium was discarded and the formazan 
products were dissolved by DMSO. The optical density (OD) at $540 \mathrm{~nm}$ was measured by a microplate reader (Molecular Device, CA, USA). Cell viability was represented as $\%$ by calculating the relative OD ratio of each experimental group to the corresponding control. The mean OD of the control group was assigned as $100 \%$.

2.6. Western Blot Analysis. Harvested cells and pulverized dorsal skin samples were lysed and homogenated with RIPA buffer $(150 \mathrm{mM} \mathrm{NaCl}, 0.5 \%$ Triton X-100, $50 \mathrm{mM}$ Tris- $\mathrm{HCl}$ (pH 7.4), $20 \mathrm{mM}$ EGTA, $1 \mathrm{mM}$ dithiothreitol, and $1 \mathrm{mM}$ $\mathrm{Na}_{3} \mathrm{VO}_{4}$ ) containing protease inhibitor cocktail (Roche Diagnostics, Mannheim, Germany). Protein samples were prepared by centrifugation at $14,000 \mathrm{~g}$ for $15 \mathrm{~min}$, and their concentrations were determined by BCA protein assay (Pierce, Rockford, IL, USA). The proteins were electrophoresised on SDS-PAGE gels and blotted onto polyvinylidene fluoride (PVDF) membranes. The membranes were blocked with 5\% skim milk in PBS containing $0.01 \%$ Tween 20 (PBST) and subsequently incubated with primary antibodies overnight at $4^{\circ} \mathrm{C}$. The immunoreactive bands were detected by using horseradish peroxidase- (HRP-) conjugated secondary antibody and enhanced chemiluminescence (ECL) reagent (Amersham Bioscience, NJ, USA). The images were captured and analyzed by ImageQuant LAS 4000 Multi Gauge software (Fujifilm, Tokyo, Japan). Data are representative of three independent experiments, which gave rise to a similar trend.

2.7. $P G E_{2}$ Assay. The $\mathrm{PGE}_{2}$ levels in the culture medium and serum were determined by a commercially available $\mathrm{PGE}_{2}$ enzyme immunoassay (EIA) kit (Cayman Chemical, CA, USA) according to the manufacturer's instructions. In brief, after treatment of SFE-EtOAc and irradiation with $\mathrm{UVB}$, the culture medium and serum were collected and transferred to a plate precoated with goat polyclonal antimouse IgG. In the next step, anti-PGE 2 monoclonal antibody and acetylcholinesterase linked to $\mathrm{PGE}_{2}$ (AchE tracer) were added and incubated for $18 \mathrm{~h}$ at $4^{\circ} \mathrm{C}$. The plate was rinsed three times with washing buffer and then reacted with Ellman's reagent for $1 \mathrm{~h}$ at room temperature. The absorbance of mixture at $405 \mathrm{~nm}$ was monitored by spectrophotometric microplate reader. The relative $\mathrm{PGE}_{2}$ concentrations were calculated by using $\mathrm{PGE}_{2}$ as a standard.

2.8. Nitrite Assay. As NO in itself is labile with very short half life, to determine $\mathrm{NO}$ generation, the concentrations of nitrite in the medium and serum were measured by Griess assay. The collected culture medium and serum were mixed with the same volume of Griess reagent $(0.1 \% N$-(1-naphthyl) ethylendiamine and $1 \%$ sulfanilamide in $5 \%$ phosphoric acid) and incubated for $10 \mathrm{~min}$ at room temperature. The absorbance of mixture at $540 \mathrm{~nm}$ was determined by microplate reader. The relative nitrite concentrations were calculated by using sodium nitrite $\left(\mathrm{NaNO}_{2}\right)$ as a standard.

2.9. Quantification of Intracellular Reactive Oxygen Species (ROS) Levels. The intracellular accumulation of ROS was measured by DCF-DA dye. DCF-DA easily diffuses into the cell and then is hydrolyzed by an intracellular esterase to DCF which can react with peroxides to produce fluorescence. SFE-EtOAc or vehicle-pretreated and UVB-exposed HaCaT cells were loaded with DCF-DA solution (50 $\mu \mathrm{M}$ in PBS) for 15 min, washed three times in PBS, and lysed with DMSO. The fluorescence intensity was monitored by fluorescence microplate reader (Gemini XS, Molecular Devices Co., USA) with excitation at $488 \mathrm{~nm}$ and emission at $535 \mathrm{~nm}$. The fluorescence values were expressed as a percentage considering nonirradiated DCF-DA-stained cells as $100 \%$.

2.10. Reverse-Transcriptase Polymerase Chain Reaction (RT$P C R)$. The mRNA expression of antioxidant enzymes was assessed by RT-PCR. Total RNA was extracted using Trizol reagent (Invitrogen Co., CA, USA) and then converted to cDNA using a Reverse Transcription System (Promega, Madison, WI, USA). The target cDNA was amplified by using the following primers: catalase (CAT), forward $5^{\prime}$-CCG ACG AGA TGG CAC ACT TTG ACA- $3^{\prime}$ and reverse $5^{\prime}$ CGC GAG CAC GGT AGG GAC AGT TC-3'; copper/zincsuperoxide dismutase ( $\mathrm{Cu} / \mathrm{Zn}-\mathrm{SOD})$, forward $5^{\prime}$-CCA TCA ATA TGG GGA CAA TAC AC- $3^{\prime}$ and reverse $5^{\prime}$-ACA CGA TCT TCA ATG GAC AC-3'; glyceraldehyde 3-phosphate dehydrogenase (GAPDH), forward $5^{\prime}$-GCC AAG GTC ATC CAT GAC AAC- $3^{\prime}$ and reverse $5^{\prime}$-AGT GTA GCC CAG GAT GCC CTT- $3^{\prime}$. The amplification was carried out at $95^{\circ} \mathrm{C}$ for $30 \mathrm{~s}$ (denaturation), $61^{\circ} \mathrm{C}(\mathrm{CAT}), 49^{\circ} \mathrm{C}(\mathrm{Cu} / \mathrm{Zn}$ SOD), $57^{\circ} \mathrm{C}$ (GAPDH) for $1 \mathrm{~min}$ (annealing), and $72^{\circ} \mathrm{C}$ for $1 \mathrm{~min}$ (extension). After 33 cycles of reactions, the PCR products were separated by electrophoresis on $1.5 \%$ agarose gel at $50 \mathrm{~V}$ for $30 \mathrm{~min}$. Gels were then stained with ethidium bromide (EtBr) and visualized by UV light using Quantity One Software of Image analysis Gel Doc XR System (BIORAD, CA, USA).

2.11. Statistical Analysis. Each data point represents the mean \pm SD from at least three independent experiments. Statistical comparisons among groups were conducted by one-way analysis of variance (ANOVA) followed by Tukey's post hoc test. A value of $P$ less than 0.05 was regarded as statistically significant in all experiments.

\section{Results}

3.1. Attenuation of UVB-Induced Cytotoxicity by Ethylacetate Fraction of SF Ethanol Extract in $\mathrm{HaCaT}$ Cells. To assess the protective effect of ethylacetate fraction of SF ethanol extract (SFE-EtOAc) on the UVB-induced cytotoxicity, relative cell viability was determined by MTT dye reduction assay. The UVB irradiation $\left(60 \mathrm{~mJ} / \mathrm{cm}^{2}\right)$ alone decreased the cell viability in $\mathrm{HaCaT}$ human keratinocytes when compared with the vehicle-treated control group (1\% DMSO), which was significantly restored by pretreatment with SFEEtOAc in a concentration-dependent manner $(30 \mu \mathrm{g} / \mathrm{mL}$ and $100 \mu \mathrm{g} / \mathrm{mL}$ ) (Figure 1). Under the same experimental condition, we confirmed that vehicle alone did not cause any significant alterations in the cell viability. SFE-EtOAc substantially 


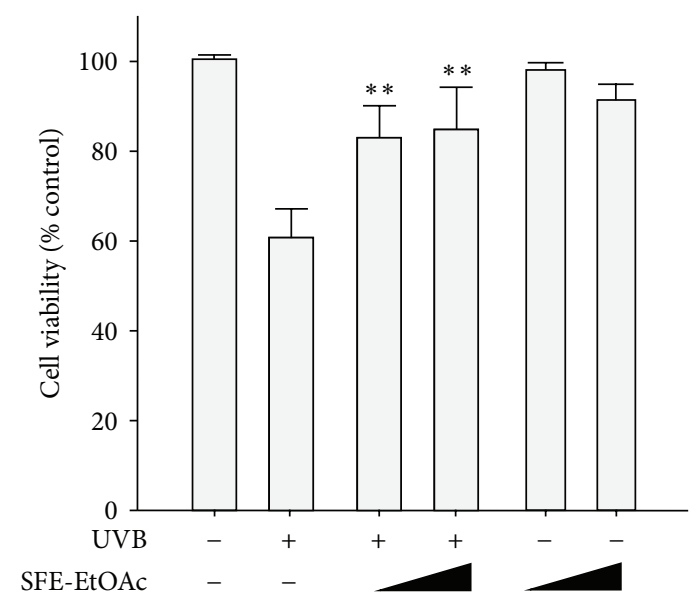

Figure 1: Protective effect of ethylacetate fraction of SF ethanol extract (SFE-EtOAc) against UVB-induced cytotoxicity in HaCaT cells. HaCaT cells were preincubated with vehicle or SFE-EtOAc $(30 \mu \mathrm{g} / \mathrm{mL}$ and $100 \mu \mathrm{g} / \mathrm{mL})$ for $9 \mathrm{~h}$ prior to UVB $\left(60 \mathrm{~mJ} / \mathrm{cm}^{2}\right)$ exposure. Twenty-four hours after UVB exposure, cell viability was measured by the MTT dye reduction assay. Cell viability is expressed as the percentage of control. Data are shown as mean \pm SD values $(n=3) .{ }^{* *} P<0.01$ compared with UVB-exposed group.

ameliorated UVB-induced cytotoxicity without exhibiting apparent self-toxicity when treated alone (Figure 1). This result provides cytoprotective potential of SFE-EtOAc against UVB irradiation-induced cellular damage and death.

\subsection{Inhibitory Effect of SFE-EtOAc on UVB-Induced Expres-} sion of COX-2 and TNF- $\alpha$ and Production of $P G E_{2}$ in $\mathrm{HaCaT}$ Cells. To analyze whether SFE-EtOAc could inhibit UVBinduced pro-inflammatory damages in $\mathrm{HaCaT}$ cells, the protein expression of COX-2 and TNF- $\alpha$ and subsequent production of $\mathrm{PGE}_{2}$ were measured by western blot analysis and ELISA, respectively. The maximal induction time point for the protein expression of COX-2 and TNF- $\alpha$ by UVB irradiation $\left(60 \mathrm{~mJ} / \mathrm{cm}^{2}\right)$ was determined by kinetic profiles of western blot analysis. Single UVB exposure markedly enhanced protein levels of COX-2 and TNF- $\alpha$ (Figure 2(a)) and increased $\mathrm{PGE}_{2}$ levels released into the media (Figure 2(b)) at $24 \mathrm{~h}$, which were effectively suppressed by increasing concentrations of SFE-EtOAc pretreatment $(30 \mu \mathrm{g} / \mathrm{mL}$ and $100 \mu \mathrm{g} / \mathrm{mL})$. At $100 \mu \mathrm{g} / \mathrm{mL}$ of SFE-EtOAc, the COX-2 and TNF- $\alpha$ expression (Figure 2(a)) and $\mathrm{PGE}_{2}$ production (Figure 2(b)) were almost abolished to vehicletreated control levels. These results suggest a strong antiinflammatory potential of SFE-EtOAc against UVB irradiation.

3.3. Inhibitory Effect of SFE-EtOAc on UVB-Induced iNOS Expression and NO Production in HaCaT Cells. To further examine the anti-inflammatory activity of SFE-EtOAc against UVB irradiation, the protein levels of iNOS and subsequent generation of NO were assessed by western blot analysis and Griess assay, respectively. The optimal time to compare the protein expression of iNOS was determined based on a time course profile of western blot analysis. When
HaCaT keratinocytes were exposed to UVB $\left(60 \mathrm{~mJ} / \mathrm{cm}^{2}\right)$, iNOS protein expression was markedly increased and SFEEtOAc pretreatment $(30 \mu \mathrm{g} / \mathrm{mL}$ and $100 \mu \mathrm{g} / \mathrm{mL})$ before UVB irradiation resulted in an effective inhibition of iNOS protein levels (Figure 3(a)). Furthermore, the amount of NO released into the media was relatively higher in the UVB-irradiated group, which was significantly reduced by pretreatment with SFE-EtOAc (Figure 3(b)).

3.4. Inhibitory Effect of SFE-EtOAc on UVB-Induced Expression of COX-2 and TNF- $\alpha$ and Production of $P G E_{2}$ in $B A L B / c$ Mice. In order to confirm the anti-inflammatory effect of SFE-EtOAc against UVB-stimulated inflammatory responses in vivo, $\mathrm{BALB} / \mathrm{c}$ mice were exposed to UVB $\left(200 \mathrm{~mJ} / \mathrm{cm}^{2}\right)$ with or without pretreatment of SFE-EtOAc $(3 \mu \mathrm{g}$ and $10 \mu \mathrm{g}$ ) for $30 \mathrm{~min}$. After UVB irradiation the protein expression of COX-2 and TNF- $\alpha$ in the mouse skin was markedly increased when compared with vehicle-treated control animals (acetone-olive oil $3: 1$ ) (Figure 4(a)). The elevated protein levels of COX- 2 and TNF- $\alpha$ were gradually decreased by topical application of SFE-EtOAc in a doserelated manner (Figure 4(a)). In accordance with COX-2 protein expression, SFE-EtOAc treatment significantly downregulated UVB-induced $\mathrm{PGE}_{2}$ production in $\mathrm{BALB} / \mathrm{c}$ mice almost to control levels (Figure 4(b)).

3.5. Inhibitory Effect of SFE-EtOAc on UVB-Induced iNOS Expression and NO Production in $B A L B / c$ Mice. To investigate the inhibitory effect of SFE on the UVB-induced iNOS expression and NO production, BALB/c mice were pretreated with vehicle or SFE-EtOAc $(3 \mu \mathrm{g}$ and $10 \mu \mathrm{g})$ for $30 \mathrm{~min}$ before exposure to UVB $\left(200 \mathrm{~mJ} / \mathrm{cm}^{2}\right)$. UVB irradiation alone increased protein expression of iNOS comparing with vehicle-treated control animals (acetone-olive oil $3: 1$ ), whereas topical application of SFE-EtOAc effectively suppressed UVB-elevated protein levels of iNOS as assessed by western blot analysis (Figure 5(a)). Alike result of iNOS expression, SFE-EtOAc significantly inhibited the production of NO to a level commensurate with UVB-unstimulated vehicle-treated control (Figure 5(b)).

3.6. Augmentation of Cellular Antioxidant Defense Enzymes by SFE-EtOAc. When the skin is exposed to excess UVB, as one of the first events, ROS is generated in keratinocytes, which consequently leads to pro-inflammatory process and other biochemical reactions related to oxidative stress. Therefore, in the next experiment, to evaluate the antioxidant activity of SFE-EtOAc as a protective molecular mechanism, intracellular accumulation of RSO and the mRNA expression of antioxidant enzymes were measured by conducting DCF-DA staining and RT-PCR, respectively. In HaCaT cells, SFE-EtOAc $(30 \mu \mathrm{g} / \mathrm{mL}$ and $100 \mu \mathrm{g} / \mathrm{mL})$ pretreatment effectively reduced UVB-increased intracellular ROS levels (Figure 6(a)) and highly upregulated mRNA levels of antioxidant enzymes such as CAT and Cu/Zn-SOD (Figure 6(b)). These results suggest that SFE-EtOAc exhibits strong antioxidant potential via fortifying cellular antioxidant defense capacity thereby 


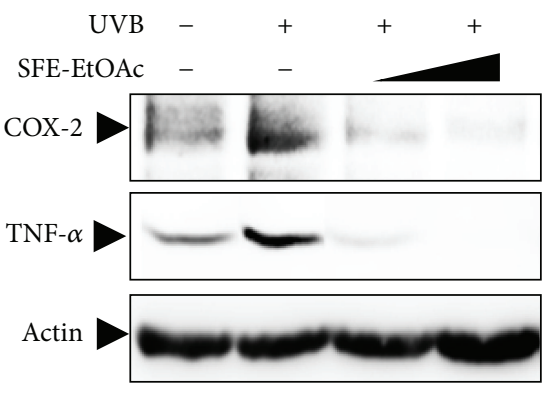

(a)

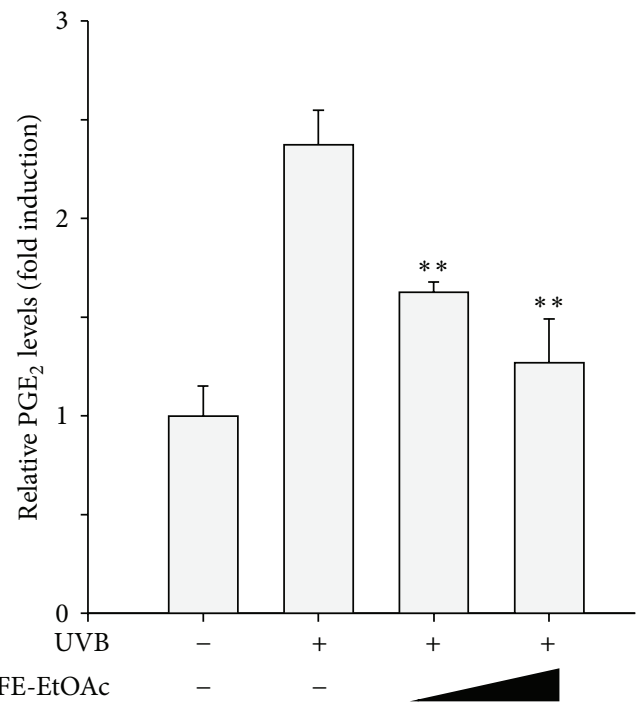

(b)

FIGURE 2: Inhibition of UVB-induced COX-2 and TNF- $\alpha$ expressions and subsequent $\mathrm{PGE}_{2}$ production by SFE-EtOAc in HaCaT cells. HaCaT cells were pretreated with vehicle or SFE-EtOAc $(30 \mu \mathrm{g} / \mathrm{mL}$ and $100 \mu \mathrm{g} / \mathrm{mL})$ for $9 \mathrm{~h}$ before irradiation of UVB $\left(60 \mathrm{~mJ} / \mathrm{cm}^{2}\right)$. Twenty-four hours after UVB exposure $\left(60 \mathrm{~mJ} / \mathrm{cm}^{2}\right)$, the protein expression of COX-2 and TNF- $\alpha$ (a) and accumulation of PGE 2 into the media (b) were monitored by western blot analysis and ELISA, respectively. (a) Protein extracts were loaded onto a SDS-PAGE and then transferred to PVDF membranes. The membranes were probed with anti-COX-2, anti-TNF- $\alpha$, or antiactin primary antibody. Actin levels were assessed to confirm the equal amount of protein loading. Representative blots from three independent experiments are shown. (b) The relative levels of the PGE 2 were represented as fold induction in comparison with the vehicle-treated control cells. Asterisks indicate a significant difference from the group exposed to UVB alone $\left({ }^{* *} P<0.01\right)$.

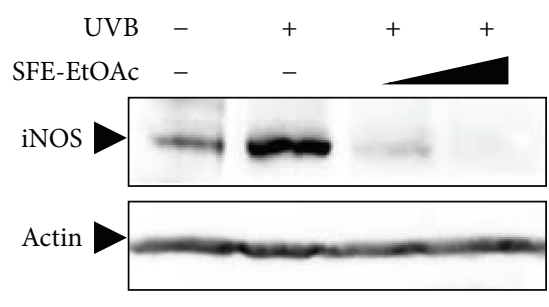

(a)

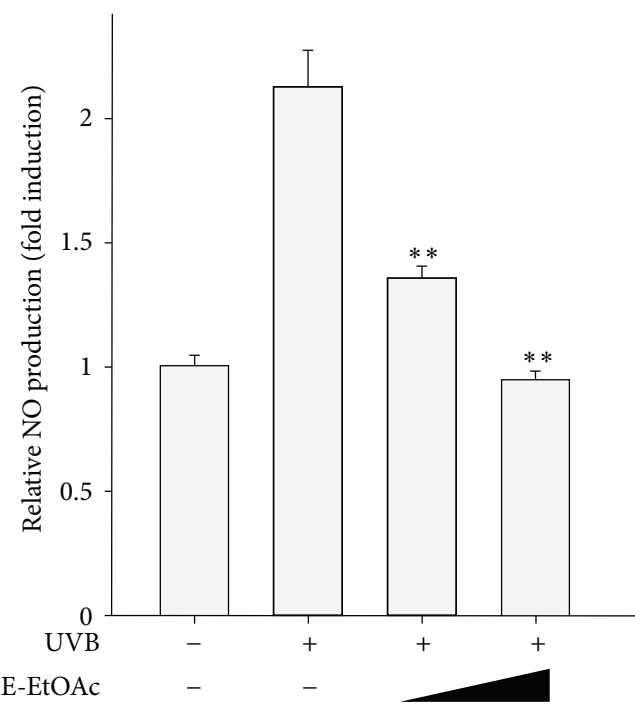

(b)

FIgURE 3: Inhibition of UVB-induced iNOS expression and subsequent NO production by SFE-EtOAc in HaCaT cells. HaCaT cells were pretreated with vehicle or SFE-EtOAc $(30 \mu \mathrm{g} / \mathrm{mL}$ and $100 \mu \mathrm{g} / \mathrm{mL})$ for $9 \mathrm{~h}$ and then exposed to UVB $\left(60 \mathrm{~mJ} / \mathrm{cm}^{2}\right)$. Thereafter, media were replaced with fresh media containing SFE-EtOAc or vehicle, and cells were additionally incubated for $24 \mathrm{~h}$. (a) Western blot analysis was performed using anti-iNOS or antiactin primary antibody. Representative blots from three independent experiments are shown. The actin levels were monitored for the confirmation of equal amount of protein loading. (b) The NO levels released into the medium were measured by Griess assay as described in Section 2. The relative levels of the NO production were represented as fold induction in comparison with the vehicle-treated control cells $(4.28 \pm 0.18 \mu \mathrm{M})$. Asterisks indicate a significant difference compared with UVB-irradiated group $\left({ }^{* *} P<0.01\right)$. 


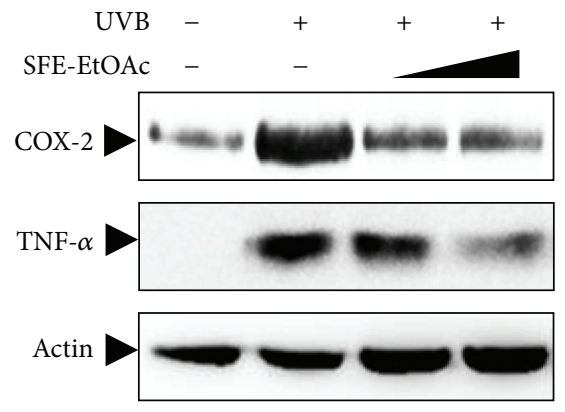

(a)

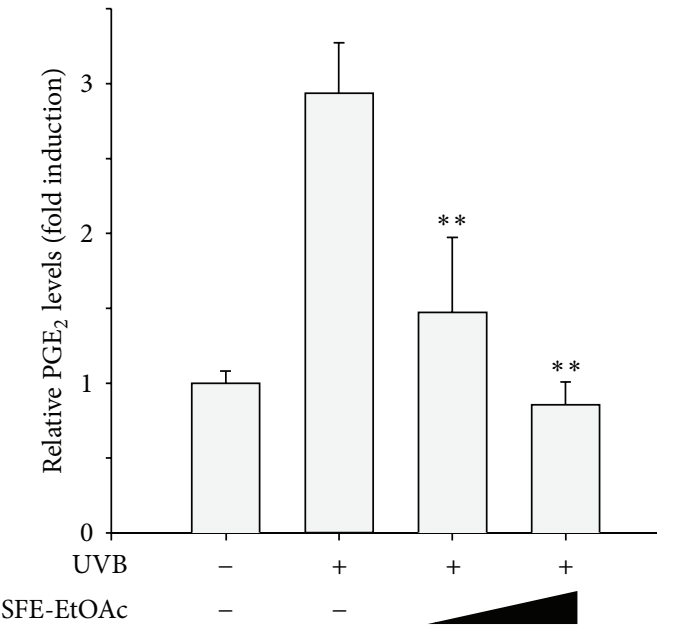

(b)

FIGURE 4: Inhibition of UVB-induced COX-2 and TNF- $\alpha$ expression and subsequent PGE $_{2}$ production by SFE-EtOAc in mouse skin. SFEEtOAc $(3 \mu \mathrm{g}$ and $10 \mu \mathrm{g})$ dissolved in acetone-olive oil $(1: 3)$ was topically applied to BALB/c mice 30 min before UVB $\left(200 \mathrm{~mJ} / \mathrm{cm}^{2}\right) \mathrm{stimulation}$. Twenty-four hours later, skin samples were excised from the backs of mice. (a) Protein levels of COX-2 and TNF- $\alpha$ were determined by western blot analysis using anti-COX-2 and anti-TNF- $\alpha$ antibodies. Actin was detected to verify equal protein loading. (b) The PGE 2 levels in serum were measured by ELISA as described in Section 2. The relative $\mathrm{PGE}_{2}$ levels were shown as fold induction from the vehicle-treated sham control. Asterisks indicate a significant difference from the value obtained with UVB alone $\left({ }^{* *} P<0.01\right)$. For sham control and UVB alone-irradiated groups, same amount of vehicle (acetone-loive oil) was topically applied instead of SFE-EtOAc solution.

possibly protecting against UVB-induced inflammatory and oxidative damages.

\section{Discussion}

Exposure to solar UVB radiation induces an array of adverse reactions in the skin such as edema, erythema, hyperplastic responses, sunburn, photoaging, and cancer via altered intracellular signaling related with inflammation and oxidative stress. Therefore, the amelioration of UVB-induced inflammatory and oxidative responses represents a potential strategy for the prevention and protection against UVBinduced cellular and tissue photodamages. In this regards, recently a wide variety of edible and medicinal plants have been investigated for topical application. The present study demonstrates the inhibitory effect of Sargassum fulvellum (SF) against UVB-induced proinflammatory skin damages, suggesting the potential photoprotective effect of SF in UVBirradiated $\mathrm{HaCaT}$ cells in vitro as well as mouse skin in vivo.

Keratinocytes respond to the major changes in the inflammation and immunomodulation observed after UVB exposure, at least in part via the UVB-induced expression of inflammatory enzymes and release of pro-inflammatory mediators. COX-2 plays a key role in acute UVB-induced inflammation by catalyzing the generation of $\mathrm{PGE}_{2}$ from prostanoid precursors. The present study demonstrates that in human keratinocyte $\mathrm{HaCaT}$ cells and $\mathrm{BALB} / \mathrm{c}$ mouse skin, ethylacetate fraction of SF ethanol extract (SFE-EtOAc) effectively inhibited UVB-triggered COX-2 expression and subsequent $\mathrm{PGE}_{2}$ synthesis.

In accordance with our experimental data, the expression of COX-2 is significantly elevated in $\mathrm{HaCaT}$ human keratinocytes [14-16] and JB6 P+ mouse epidermal cells
[17] after a single exposure to UVB and sulforaphane [14], $\gamma$-tocotrienol [15], luteolin [16], and delphinidin [17] have been shown to suppress UVB-induced COX-2 expression and subsequent formation of PG metabolites. Stimulation of HR$1[14,15,18,19]$ and SKH-1 [20] hairless mouse skin with UVB resulted in a significant increase in COX-2 expression and conversely topical application of sulforaphane [14], $\gamma$ tocotrienol [15], anthocyanins from black soybean seed coats [18], oligonol [19], and proanthocyanidins from grape [20] inhibited UVB-induced COX-2 expression.

Furthermore, exposure of the skin to UVB radiation is known to enhance the levels of pro-inflammatory cytokines. As keratinocytes are considered to be major sources of cytokines, chemokines, growth factors, and many others, UVB radiation can cause a series of changes in the cutaneous cytokine micromilieu such as TNF- $\alpha$, IL- $1 \alpha$, IL- $1 \beta$, IL- 6 , and IL-8 [3]. In this study, UVB markedly induced the protein expression of TNF- $\alpha$ in $\mathrm{HaCaT}$ cells and BALC/c mice, which was effectively suppressed by pretreatment of SFEEtOAc. TNF- $\alpha$ is a major cytokine involved in the early stage of inflammation released when keratinocytes are damaged and stimulates neighboring keratinocytes to amplify the responses.

In line with our notion, previous in vitro and in vivo laboratory studies have shown the photoprotective effects of natural products by suppressing UVB-induced expression of diverse cytokines. Water extract of Zingiber officinale, gingerol, and shogaol inhibited production of cytokines such as TNF- $\alpha$, IL-1 $\beta$, IL-6, and IL- 8 in UVB-irradiated HaCaT cells and hyperplasia, infiltration of leukocytes, and dilation of blood vessels in UVB-exposed C57BL/6 mice [3]. Tannic acids attenuated UVB-induced cutaneous inflammation in $\mathrm{HaCaT}$ cells by inhibiting UVB-enhanced expression of cytokines including TNF- $\alpha$, IL-1 $\beta$, IL-6, and IL-18 [21]. 


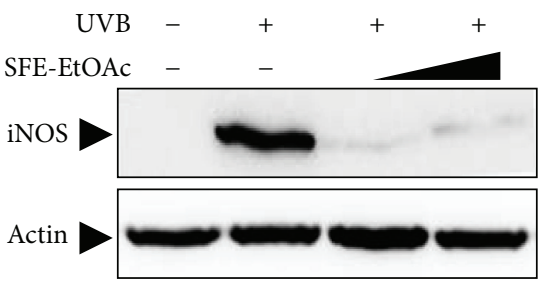

(a)

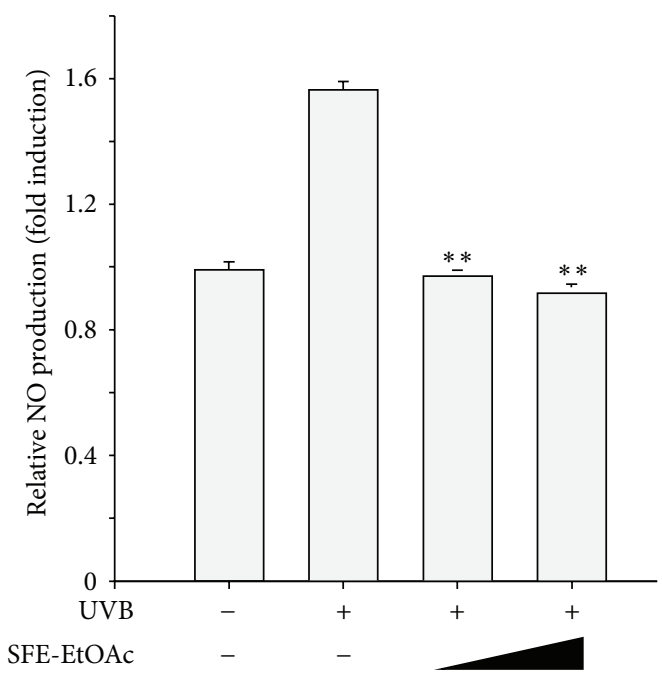

(b)

FIgURE 5: Inhibition of UVB-induced iNOS expression and subsequent NO production by SFE-EtOAc in mouse skin. Prior to UVB $\left(200 \mathrm{~mJ} / \mathrm{cm}^{2}\right)$ irradiation SFE-EtOAc $(3 \mu \mathrm{g}$ and $10 \mu \mathrm{g})$ was topically applied on the back of BALB/c mice for 30 min. Twenty-four hours later, skin samples were excised from the backs of mice. (a) Protein expression of iNOS was determined by western blot analysis using iNOS-specific primary antibody. Actin was detected to verify equal protein loading. (b) The NO levels in serum were assessed by Griess assay as indicated in Section 2. The relative NO production was represented as fold induction in comparison with the vehicle-treated sham control group. Asterisks indicate a significant difference from the value obtained with UVB alone $\left({ }^{* *} P<0.01\right)$. For sham control and UVB alone-irradiated groups, same amount of vehicle (acetone-loive oil) was topically applied instead of SFE-EtOAc solution.

In addition, iNOS expression and activity have been reported to play an important role in various skin disorders such as sunburn erythema, psoriasis, cutaneous lupus erythematosus, and squamous cell carcinoma $[6,22]$. The expression of iNOS is induced in response to microbial infection, cytokine stimulation, and environmental insults in a variety of cell types including keratinocytes and subsequently involved in the release NO [6]. NO is first recognized as a paracrine regulator of diverse biological responses such as smooth muscle relaxation, vasodilation, neurotransmission, immunomodulation, and modification of cellular proliferation [6]. However, excess production of NO can exert toxic effects via induction of oxidative stress, DNA damage, and apoptosis by its direct action or indirect formation of more potent oxidant, peroxynitrite $\left(\mathrm{ONOO}^{-}\right)[23]$.

Our findings demonstrate that UV radiation is capable of induction of iNOS accompanying subsequent NO release in $\mathrm{HaCaT}$ keratinocytes and BALB/c mice, and SFEEtOAc treatment prior to UV exposure markedly decreased UVB-induced expression of iNOS and production of NO. Treatment of human keratinocytes with amniotic membrane extract [7] and human melanocytes with ferulic acid ethyl ester [24] also has been shown to result in a reduction of iNOS expression as well as NO generation thereby protecting cells from UVB-induced oxidative damage and cell death.

The UVB-induced inappropriate overexpression of COX2 , cytokines, and iNOS results from dysregulation of intracellular signal transduction pathways mediated by various transcription factors and upstream kinases. Previous studies demonstrated that NF- $\kappa$ B activation was observed in UVBstimulated $\mathrm{HaCaT}$ cells in vitro and mouse skin in vivo. In
$\mathrm{HaCaT}$ cells, [6]-gingerol, a pungent ingredient of ginger [2], and docosahexaenoic acid, a representative $\omega$ - 3 polyunsaturated fatty acid in fish oil [25], effectively reduced UVBinduced expression of COX-2 by inhibiting NF- $\kappa \mathrm{B}$ activation via suppression of $\mathrm{I} \kappa \mathrm{B} \alpha$ phosphorylation. Epigallocatechin3-gallate, a green tea polyphenol, downregulated the UVBinduced iNOS mRNA synthesis and NO generation by decreasing activation and translocation of NF- $\kappa$ B [26]. Moreover, curcumin, a yellow pigment present in the rhizome of turmeric, inhibited UVB-induced expression of cytokines by suppressing the DNA binding of NF- $\kappa \mathrm{B}$ in HaCaT cells [27].

UVB irradiation results in local inflammation, which further amplifies ROS generation. ROS has been suggested to play an important role in the UVB-induced activation of COX-2. Pretreatment with $\mathrm{HaCaT}$ cells with an antioxidant $\mathrm{N}$-acetylcysteine partly inhibited UVB-induced COX2 expression [28]. Conversely, in human epidermoid keratinocytes, depletion of endogenous antioxidant reduced glutathione (GSH) augmented UVB-upregulated COX-2 expression [29]. To protect against ROS-mediated oxidative stress, the skin possesses an array of antioxidant defense system. However, chronic and excess exposure to UV radiation can overwhelm the antioxidant capacity and lead to oxidative damages to critical cellular components such as mitochondria, DNA, lipid membranes, and proteins [8].

In $\mathrm{HaCaT}$ cells, SFE-EtOAc enhanced mRNA expression of antioxidant enzymes such as CAT and $\mathrm{Cu} / \mathrm{Zn}$-SOD and augmented cellular defense capacity against oxidative stress. Catalase catalyzes the decomposition of hydrogen peroxide $\left(\mathrm{H}_{2} \mathrm{O}_{2}\right)$ to water and oxygen molecules. SOD catalyzes the dismutation of superoxide anion $\left(\mathrm{O}_{2}{ }^{-}\right)$to hydrogen peroxide 


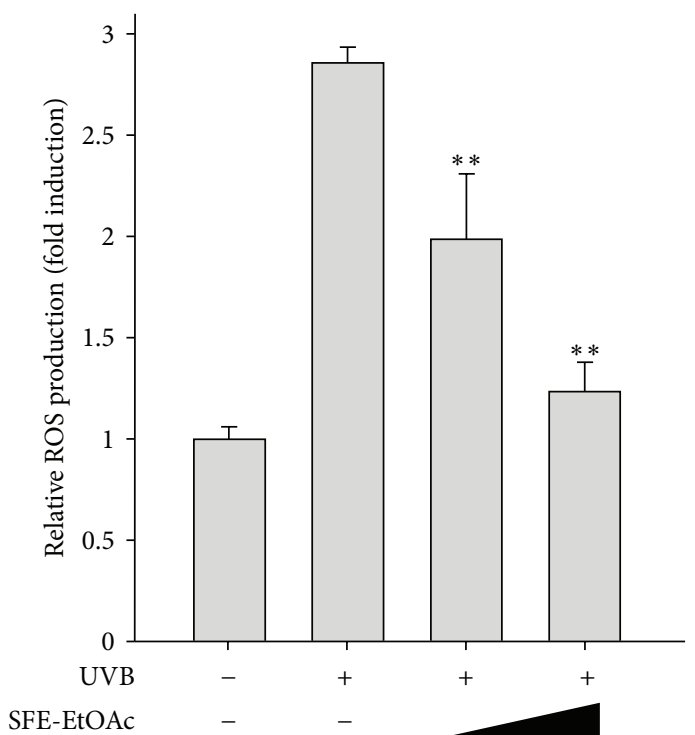

(a)
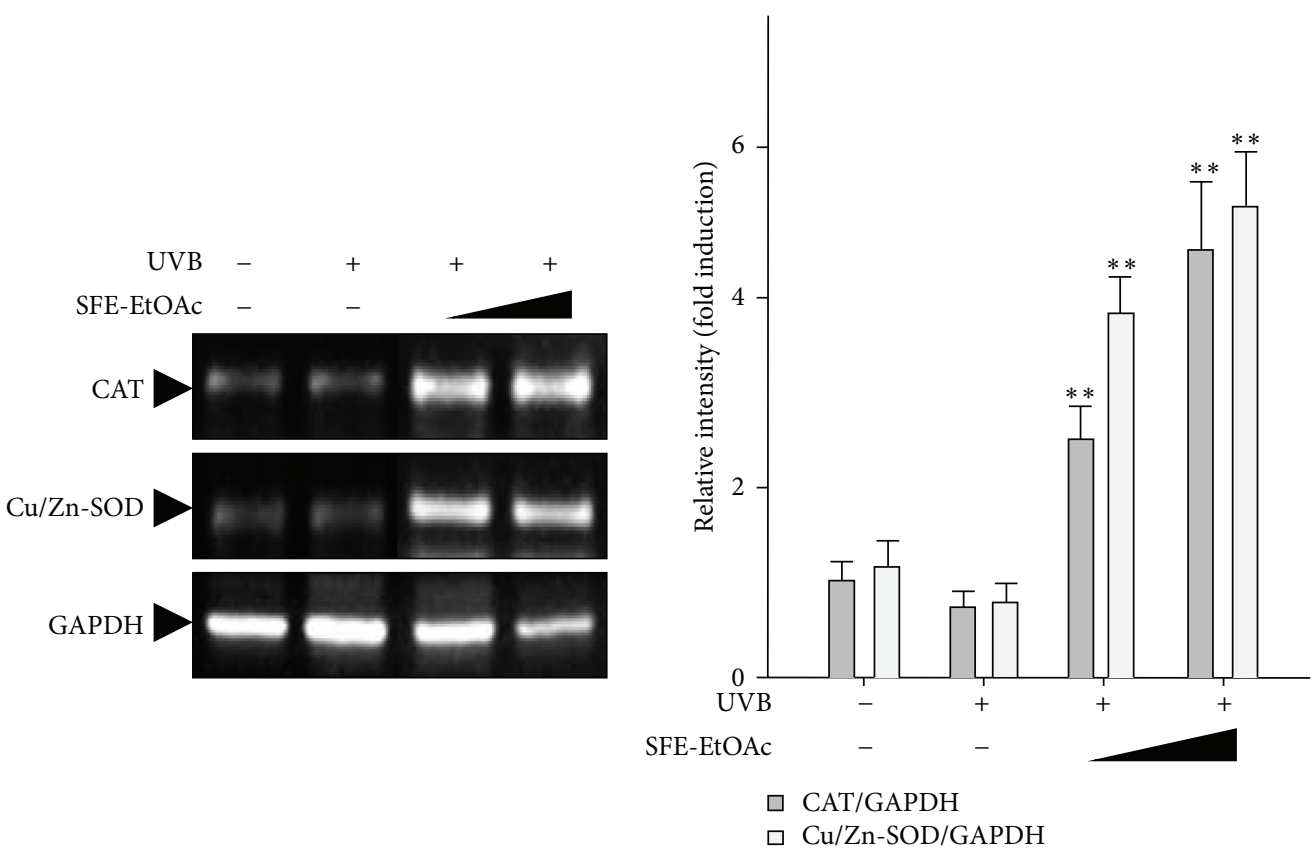

(b)

FIGURE 6: Effect of SFE-EtOAc on the intracellular ROS levels and mRNA expression of antioxidant enzymes in HaCaT cells. HaCaT cells were pretreated with vehicle or SFE-EtOAc $(30 \mu \mathrm{g} / \mathrm{mL}$ and $100 \mu \mathrm{g} / \mathrm{mL})$ for $9 \mathrm{~h}$ and then stimulated with UVB $\left(60 \mathrm{~mJ} / \mathrm{cm}^{2}\right)$. (a) Intracellular ROS generation was measured by relative fluorescence intensity using DCF-DA dye as indicated in Section 2. Data are shown as mean \pm SD values $(n=3) .{ }^{* *} P<0.01$ compared with UVB-exposed group. (b) The mRNA levels of antioxidant enzymes such as catalase and Cu/Zn-SOD were measured by RT-PCR using their specific primers. Quantification data of mRNA expression of antioxidant enzymes analyzed by RT-PCR, which was normalized by GAPDH levels as loading control. Asterisks indicate a significant difference compared with UVB-irradiated group $\left({ }^{* *} P<0.01\right)$.

thereby regulating intracellular superoxide anion levels [22]. $\mathrm{Cu} / \mathrm{Zn}$-SOD isoform exists at high levels throughout the cells particularly in the cytosol.

In line with our findings, ethyl acetate fraction of Sargassum muticum protected against UVB-induced oxidative damages by restoration of protein expression and activity of antioxidant enzymes such as CAT and $\mathrm{Cu} / \mathrm{Zn}$-SOD in HaCaT cells [9]. Moreover, methanol extract of Sargassum thunbergii protected against hydrogen peroxide-induced cytotoxicity and oxidative stress by increasing the expression of antioxidative enzymes including SOD, CAT, glutathione peroxidase (GPx), and glutathione reductase (GR) [30]. Previous studies 
have shown that extracts of three varieties of leaves from Lepidium meyenii prevented the UVB-developed sunburn, epidermal hyperplasia, leukocytic infiltration, and other alterations via augmenting antioxidant activity of SOD and CAT in male Swiss mice [31]. In human skin dermal fibroblast adult cells, the activities of enzymatic antioxidants (SOD, CAT, and GPx) and the levels of nonenzymatic antioxidants (GSH) were markedly decreased in UVB-irradiated cells, which were effectively restored by sesamol pretreatment leading to cellular protection against UVB-induced oxidative damages and apoptotic cell death [32].

However, to elucidate the intracellular signaling pathways involved in the antioxidant effect of SFE-EtOAc in $\mathrm{HaCaT}$ cells and to further confirm its antioxidant molecular mechanisms in BALB/c mice, additional research targeting redox-sensitive transcription factors and upstream regulators should be conducted. Moreover, particularly in animal models, the possibility of SFE-EtOAc acting as a UVB blocker is not ruled out and should be verified in concert with its antioxidant potentials.

\section{Conclusions}

SFE-EtOAc inhibited UVB-induced skin inflammation such as enhanced protein expression of COX-2, TNF- $\alpha$, and iNOS and subsequent production of $\mathrm{PGE}_{2}$ and $\mathrm{NO}$ in vitro $\mathrm{HaCaT}$ human keratinocytes as well as in vivo $\mathrm{BALB} / \mathrm{c}$ mice, which would provide a novel insight into the application of SFE-EtOAc for antiphotoinflammatory purposes. The antiinflammatory effect of SFE-EtOAc seemed to be mediated by, at least in part, attenuation of oxidative stress via upregulation of cellular antioxidant defense enzymes. Therefore, the topical treatment of SFE-EtOAc or routine consumption of SFE-EtOAc containing functional foods in combination with sunscreens or skin care products may be an efficient strategy for mitigating the harmful effects of excessive UVB exposures.

\section{Acknowledgment}

This research was supported by Technology Development Program for Fisheries, Ministry for Food, Agriculture, Forestry and Fisheries, Republic of Korea.

\section{References}

[1] J. A. Nichols and S. K. Katiyar, "Skin photoprotection by natural polyphenols: anti-inflammatory, antioxidant and DNA repair mechanisms," Archives of Dermatological Research, vol. 302, no. 2, pp. 71-83, 2010.

[2] J.-K. Kim, Y. Kim, K.-M. Na, Y.-J. Surh, and T.-Y. Kim, “[6]gingerol prevents UVB-induced ROS production and COX-2 expression in vitro and in vivo," Free Radical Research, vol. 41, no. 5, pp. 603-614, 2007.

[3] G.-H. Guahk, S. K. Ha, H.-S. Jung et al., "Zingiber officinale protects $\mathrm{HaCaT}$ cells and $\mathrm{C} 57 \mathrm{BL} / 6$ mice from ultraviolet $\mathrm{B}$ induced inflammation," Journal of Medicinal Food, vol. 13, no. 3, pp. 673-680, 2010.
[4] A. Nicolaou, S. M. Pilkington, and L. E. Rhodes, "Ultravioletradiation induced skin inflammation: dissecting the role of bioactive lipids," Chemistry and Physics of Lipids, vol. 164, no. 6, pp. 535-543, 2011.

[5] S. J. Burke and J. J. Collier, "The gene encoding cyclooxygenase2 is regulated by IL- $1 \beta$ and prostaglandins in $832 / 13$ rat insulinoma cells," Cellular Immunology, vol. 271, no. 2, pp. 379-384, 2011.

[6] S. J. Seo, H. G. Choi, H. J. Chung, and C. K. Hong, "Time course of expression of mRNA of inducible nitric oxide synthase and generation of nitric oxide by ultraviolet B in keratinocyte cell lines," The British Journal of Dermatology, vol. 147, no. 4, pp. 655$662,2002$.

[7] D. S. Chang, S. J. Seo, and C. K. Hong, "The effect of amniotic membrane extract on the expression of iNOS mRNA and generation of $\mathrm{NO}$ in $\mathrm{HaCat}$ cell by ultraviolet B irradiation," Photodermatology Photoimmunology and Photomedicine, vol. 18, no. 6, pp. 280-286, 2002.

[8] M. L. Paz, D. H. G. Maglio, F. S. Weill, J. Bustamante, and J. Leoni, "Mitochondrial dysfunction and cellular stress progression after ultraviolet B irradiation in human keratinocytes," Photodermatology Photoimmunology and Photomedicine, vol. 24, no. 3, pp. 115-122, 2008.

[9] M. J. Piao, W. J. Yoon, H. K. Kang et al., "Protective effect of the ethyl acetate fraction of Sargassum muticum against ultraviolet B-irradiated damage in human keratinocytes," International Journal of Molecular Sciences, vol. 12, no. 11, pp. 8146-8160, 2011.

[10] J. Y. Kang, M. N. A. Khan, N. H. Park et al., "Antipyretic, analgesic, and anti-inflammatory activities of the seaweed Sargassum fulvellum and Sargassum thunbergii in mice," Journal of Ethnopharmacology, vol. 116, no. 1, pp. 187-190, 2008.

[11] N. Kawano, Y. Egashira, and H. Sanada, "Effect of dietary fiber in edible seaweeds on the development of D-galactosamineinduced hepatopathy in rats," Journal of Nutritional Science and Vitaminology, vol. 53, no. 5, pp. 446-450, 2007.

[12] I. Yamamoto, T. Nagumo, and M. Fujihara, "Antitumor effect of seaweeds. II. Fractionation and partial characterization of the polysaccharide with antitumor activity from Sargassum fulvellum," The Japanese Journal of Experimental Medicine, vol. 47, no. 3, pp. 133-140, 1977.

[13] W. Wu, K. Hasumi, H. Peng, X. Hu, X. Wang, and B. Bao, "Fibrinolytic compounds isolated from a brown alga, Sargassum fulvellum," Marine Drugs, vol. 7, no. 2, pp. 85-94, 2009.

[14] A. Shibata, K. Nakagawa, H. Yamanoi et al., "Sulforaphane suppresses ultraviolet B-induced inflammation in HaCaT keratinocytes and HR-1 hairless mice," The Journal of Nutritional Biochemistry, vol. 21, no. 8, pp. 702-709, 2010.

[15] A. Shibata, K. Nakagawa, Y. Kawakami, T. Tsuzuki, and T. Miyazawa, "Suppression of $\gamma$-tocotrienol on UVB induced inflammation in HaCaT keratinocytes and HR-1 hairless mice via inflammatory mediators multiple signaling," Journal of Agricultural and Food Chemistry, vol. 58, no. 11, pp. 7013-7020, 2010.

[16] U. Wölfle, P. R. Esser, B. Simon-Haarhaus, S. F. Martin, J. Lademann, and C. M. Schempp, "UVB-induced DNA damage, generation of reactive oxygen species, and inflammation are effectively attenuated by the flavonoid luteolin in vitro and in vivo," Free Radical Biology and Medicine, vol. 50, no. 9, pp. 10811093, 2011.

[17] J. Y. Kwon, K. W. Lee, J.-E. Kim et al., “Delphinidin suppresses ultraviolet B-induced cyclooxygenases-2 expression through 
inhibition of MAPKK4 and PI-3 kinase," Carcinogenesis, vol. 30, no. 11, pp. 1932-1940, 2009.

[18] K. Tsoyi, B. P. Hyeong, Y. Min Kim et al., "Anthocyanins from black soybean seed coats inhibit UVB-induced inflammatory cylooxygenase-2 gene expression and PGE2 production through regulation of the nuclear factor- $\kappa \mathrm{B}$ and phosphatidylinositol 3-kinase/Akt pathway," Journal of Agricultural and Food Chemistry, vol. 56, no. 19, pp. 8969-8974, 2008.

[19] J. K. Kundu, E.-J. Chang, H. Fujii, B. Sun, and Y.-J. Surh, “Oligonol inhibits UVB-induced COX-2 expression in HR-1 hairless mouse skin-AP-1 and C/EBP as potential upstream targets," Photochemistry and Photobiology, vol. 84, no. 2, pp. 399-406, 2008.

[20] S. D. Sharma and S. K. Katiyar, "Dietary grape seed proanthocyanidins inhibit UVB-induced cyclooxygenase-2 expression and other inflammatory mediators in UVB-exposed skin and skin tumors of SKH-1 hairless mice," Pharmaceutical Research, vol. 27, no. 6, pp. 1092-1102, 2010.

[21] H. J. Park, H. J. Kim, H. J. Kwon et al., "UVB-induced interleukin- 18 production is downregulated by tannic acids in human HaCaT keratinocytes," Experimental Dermatology, vol. 15, no. 8, pp. 589-595, 2006.

[22] S. Frank, H. Kämpfer, M. Podda, R. Kaufmann, and J. Pfeilschifter, "Identification of copper/zinc superoxide dismutase as a nitric oxide-regulated gene in human ( $\mathrm{HaCaT})$ keratinocytes: Implications for keratinocyte proliferation," Biochemical Journal, vol. 346, no. 3, pp. 719-728, 2000.

[23] G. R. Aitken, J. R. Henderson, S.-C. Chang, C. J. McNeil, and M. A. Birch-Machin, "Direct monitoring of UV-induced free radical generation in $\mathrm{HaCaT}$ keratinocytes," Clinical and Experimental Dermatology, vol. 32, no. 6, pp. 722-727, 2007.

[24] F. Di Domenico, M. Perluigi, C. Foppoli et al., "Protective effect of ferulic acid ethyl ester against oxidative stress mediated by UVB irradiation in human epidermal melanocytes," Free Radical Research, vol. 43, no. 4, pp. 365-375, 2009.

[25] M. M. Rahman, J. K. Kundu, J.-W. Shin, H.-K. Na, and Y.-J. Surh, "Docosahexaenoic acid inhibits UVB-induced activation of NF- $\kappa$ B and expression of COX-2 and NOX- 4 in HR- 1 hairless mouse skin by blocking MSK1 signaling," PLoS ONE, vol. 6, no. 11, article e28065, 2011.

[26] X.-Z. Song, Z.-G. Bi, and A.-E. Xu, "Green tea polyphenol epigallocatechin-3-gallate inhibits the expression of nitric oxide synthase and generation of nitric oxide induced by ultraviolet $B$ in HaCaT cells," Chinese Medical Journal, vol. 119, no. 4, pp. 282$287,2006$.

[27] A. Grandjean-Laquerriere, S. C. Gangloff, R. Le Naour, C. Trentesaux, W. Hornebeck, and M. Guenounou, "Relative contribution of $\mathrm{nf}-\kappa \mathrm{b}$ and AP- 1 in the modulation by curcumin and pyrrolidine dithiocarbamate of the UVB-induced cytokine expression by keratinocytes," Cytokine, vol. 18, no. 3, pp. 168-177, 2002.

[28] M. Ashida, T. Bito, A. Budiyanto, M. Ichihashi, and M. Ueda, "Involvement of EGF receptor activation in the induction of cyclooxygenase-2 in HaCaT keratinocytes after UVB," Experimental Dermatology, vol. 12, no. 4, pp. 445-452, 2003.

[29] M. Soriani, P. Luscher, and R. M. Tyrrell, "Direct and indirect modulation of ornithine decarboxylase and cyclooxygenase by UVB radiation in human skin cells," Carcinogenesis, vol. 20, no. 4, pp. 727-732, 1999.
[30] J.-A. Kim, C.-S. Kong, and S.-K. Kim, "Effect of Sargassum thunbergii on ROS mediated oxidative damage and identification of polyunsaturated fatty acid components," Food and Chemical Toxicology, vol. 48, no. 5, pp. 1243-1249, 2010.

[31] C. Gonzales-Castañeda, V. Rivera, A. L. Chirinos, P. Evelson, and G. F. Gonzales, "Photoprotection against the UVB-induced oxidative stress and epidermal damage in mice using leaves of three different varieties of Lepidium meyenii (maca)," International Journal of Dermatology, vol. 50, no. 8, pp. 928-938, 2011.

[32] S. Ramachandran, N. Rajendra Prasad, and S. Karthikeyan, "Sesamol inhibits UVB-induced ROS generation and subsequent oxidative damage in cultured human skin dermal fibroblasts," Archives of Dermatological Research, vol. 302, no. 10, pp. 733-744, 2010. 


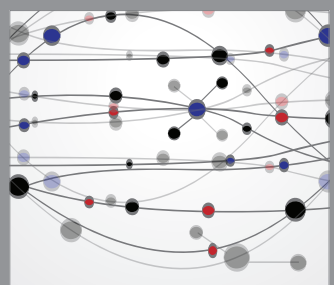

The Scientific World Journal
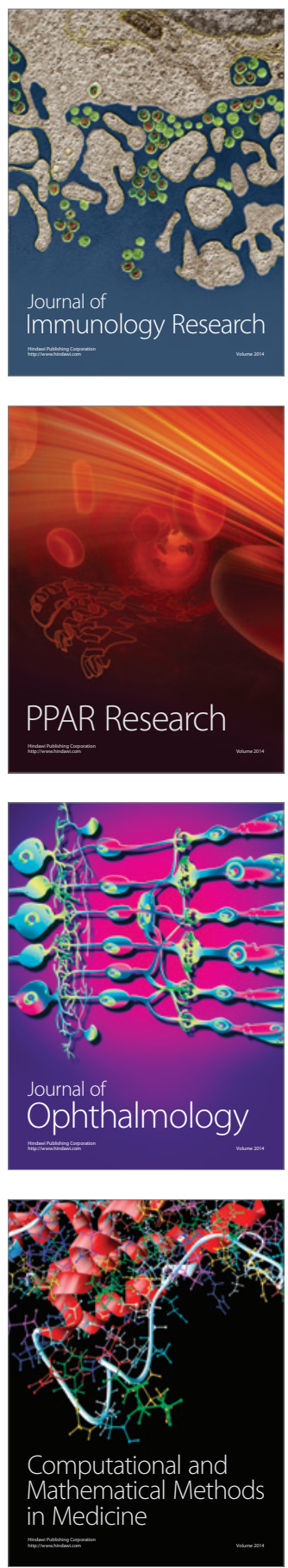

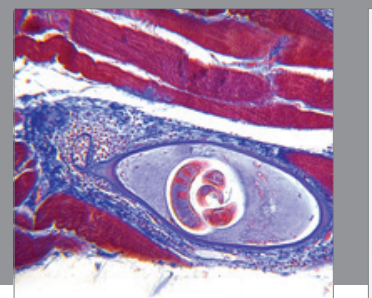

Gastroenterology

Research and Practice
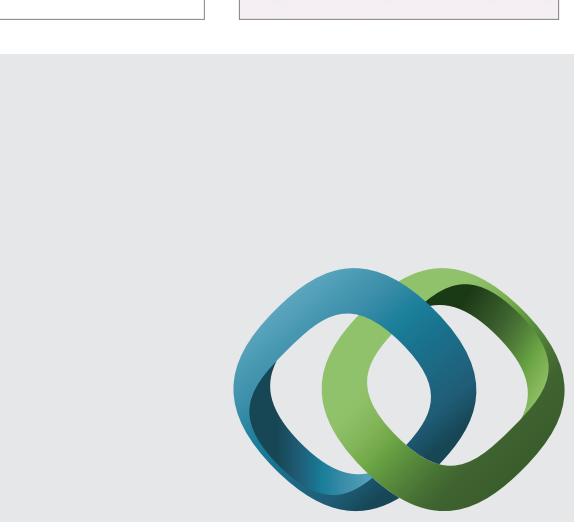

\section{Hindawi}

Submit your manuscripts at

http://www.hindawi.com
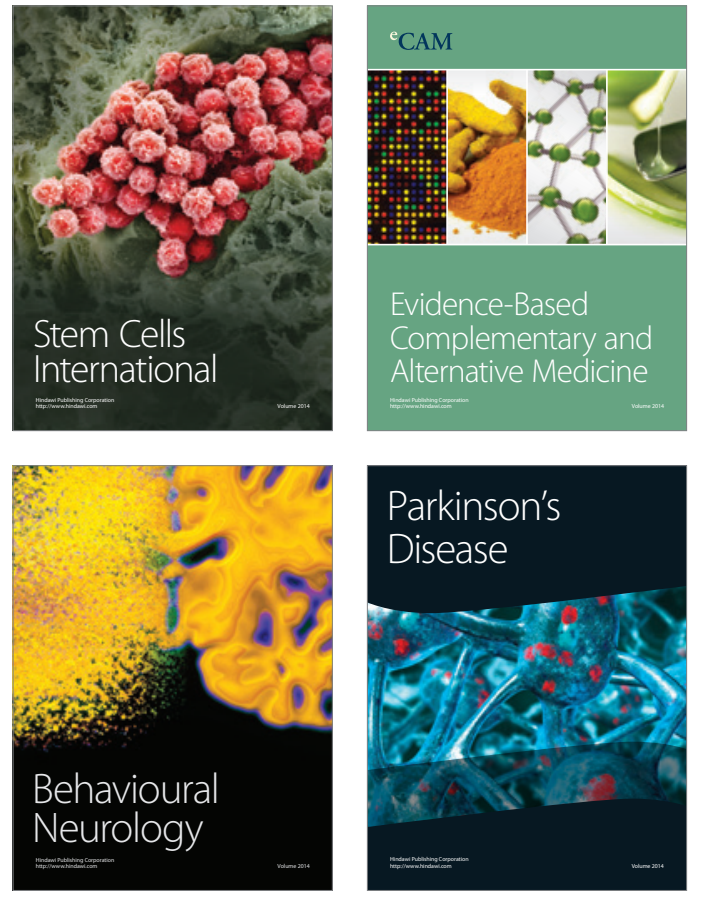
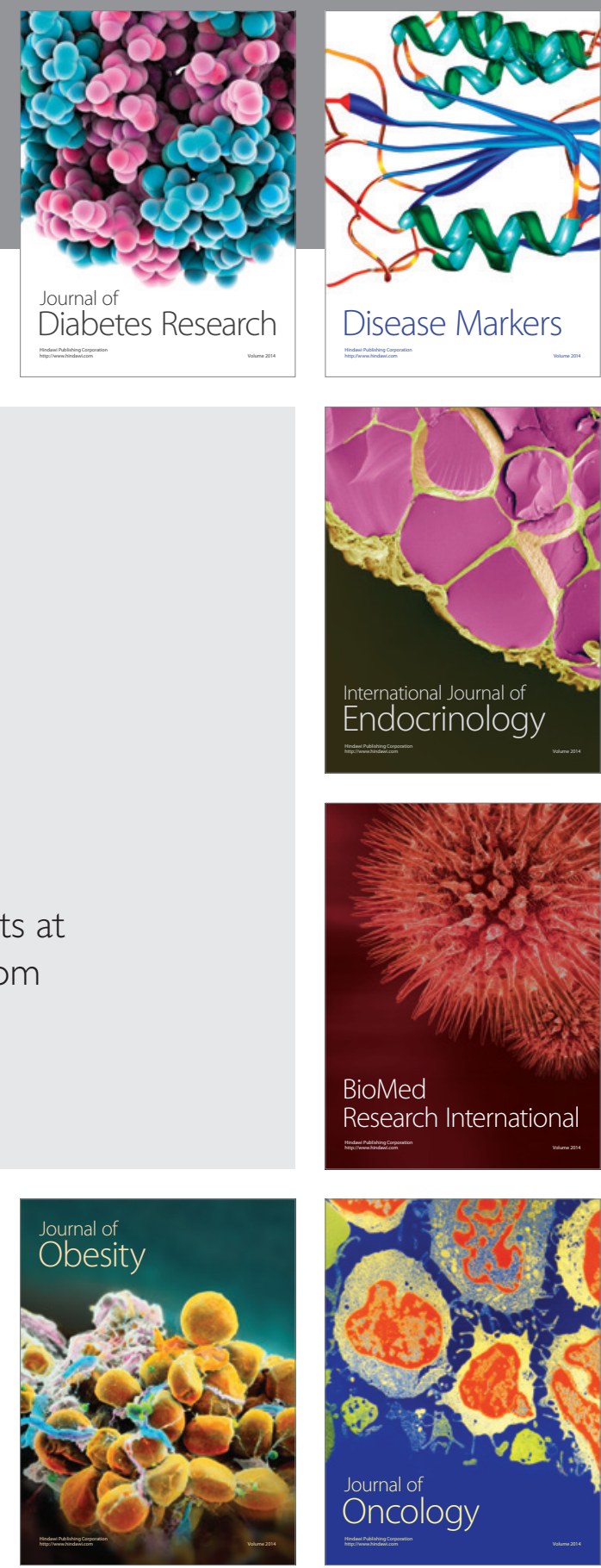

Disease Markers
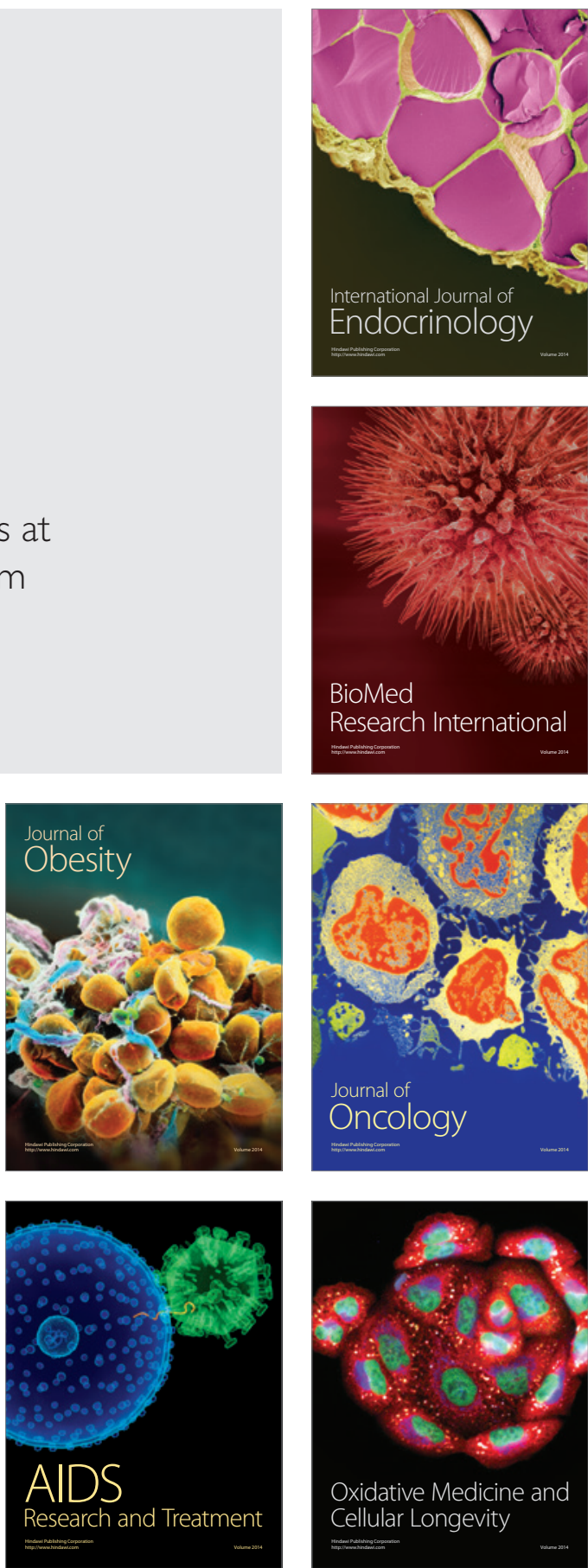